\title{
Early recovery pathway for hepatectomy: data-driven liver resection care and recovery
}

\author{
Susanne G. Warner ${ }^{1}$, Zeljka Jutric ${ }^{1}$, Liana Nisimova ${ }^{2}$, Yuman Fong ${ }^{1}$ \\ ${ }^{1}$ Division of Surgical Oncology, Department of Surgery, City of Hope National Medical Center, Duarte, CA, USA; ${ }^{2}$ Mount Sinai School of \\ Medicine, New York, NY, USA \\ Contributions: (I) Conception and design: Y Fong, SG Warner; (II) Administrative support: All authors; (III) Provision of study material or patients: \\ Y Fong; (IV) Collection and assembly of data: Y Fong, L Nisimova; (V) Data analysis and interpretation: All authors; (VI) Manuscript writing: All \\ authors; (VII) Final approval of manuscript: All authors. \\ Correspondence to: Susanne G. Warner, MD. Assistant Professor of Surgery, Division of Surgical Oncology, Department of Surgery, City of Hope \\ National Medical Center, 1500 E. Duarte Rd., MOB 1002B, Duarte, CA 91010, USA. Email: suwarner@coh.org.
}

\begin{abstract}
In recent years, great progress has been made toward safer hepatobiliary surgical interventions. This has resulted in more widely available treatments for patients who in the past were ineligible for curative resection of primary liver tumors, liver metastases, and advanced biliary tumors. However, the rise in procedures has seen increasingly heterogeneous perioperative management, yielding strikingly disparate outcomes. A number of groups have attempted to standardize perioperative care in an effort to create enhanced recovery pathways (ERPs) and provide clinicians with a dependable roadmap to success following hepatectomy. In the future, each aspect of perioperative care could be pre-ordained with emphasis on nutrition, anesthesia, prophylaxis, use of surgical drains, post-operative fluid and electrolyte management, and contact with physician extenders following discharge. This article reviews the data behind ERPs preceding and following hepatectomy. It includes primary data justifying practices in post-hepatectomy support. It also touches on the benefits of minimally invasive hepatectomy and offers future directions for research in peri-hepatectomy ERPs. Overall, this article seeks to formulate a pathway for practice based on data, with enough details to allow creation of rational order sets for efficient and superior practice.
\end{abstract}

Keywords: ERAS protocols; hepatobiliary surgery and ERAS; MIS surgery; hypophosphatemia; robotic liver surgery

Submitted Jul 08, 2016. Accepted for publication Nov 11, 2016.

doi: $10.21037 / \mathrm{hbsn} .2017 .01 .18$

View this article at: http://dx.doi.org/10.21037/hbsn.2017.01.18

\section{Introduction}

Enhanced recovery protocols for perioperative care were first explored in colorectal surgery patients after synthesis and application of known evidence-based approaches to perioperative care demonstrated improved perioperative survival (1). The resulting perioperative management strategies aim to attenuate the perioperative stress response and have been broadly adopted, resulting in improved overall outcomes and shortened length of post-operative hospital stay, thereby saving resources (2). This success has prompted the creation of a multinational collaborative of surgeons known as the Enhanced Recovery After Surgery (ERAS) Group. The ERAS Group has encouraged surgeons of many disciplines to explore enhanced recovery pathways (ERPs), including following liver resection $(3,4)$. Preliminary experience has shown that a liver ERAS "fasttrack protocol" for patients undergoing liver resection is safe, and facilitates early oral intake, faster postoperative recovery, and reduced hospital stay (4).

Researchers in peri-hepatectomy ERPs have looked closely at many different aspects of perioperative care including nutrition, anesthesia, prophylaxis, use of surgical 


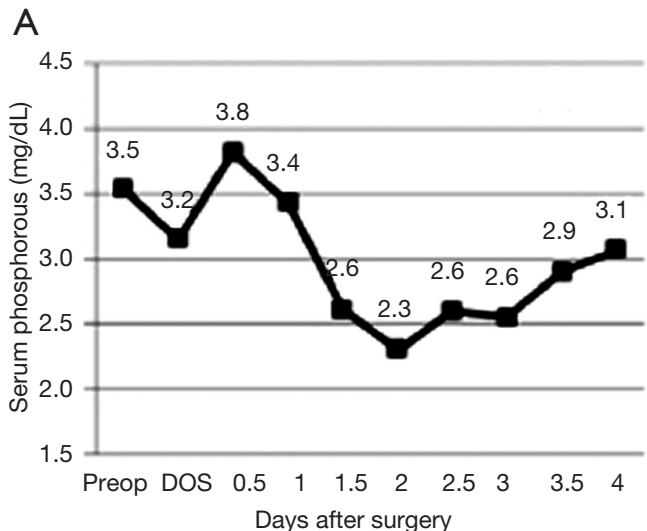

B
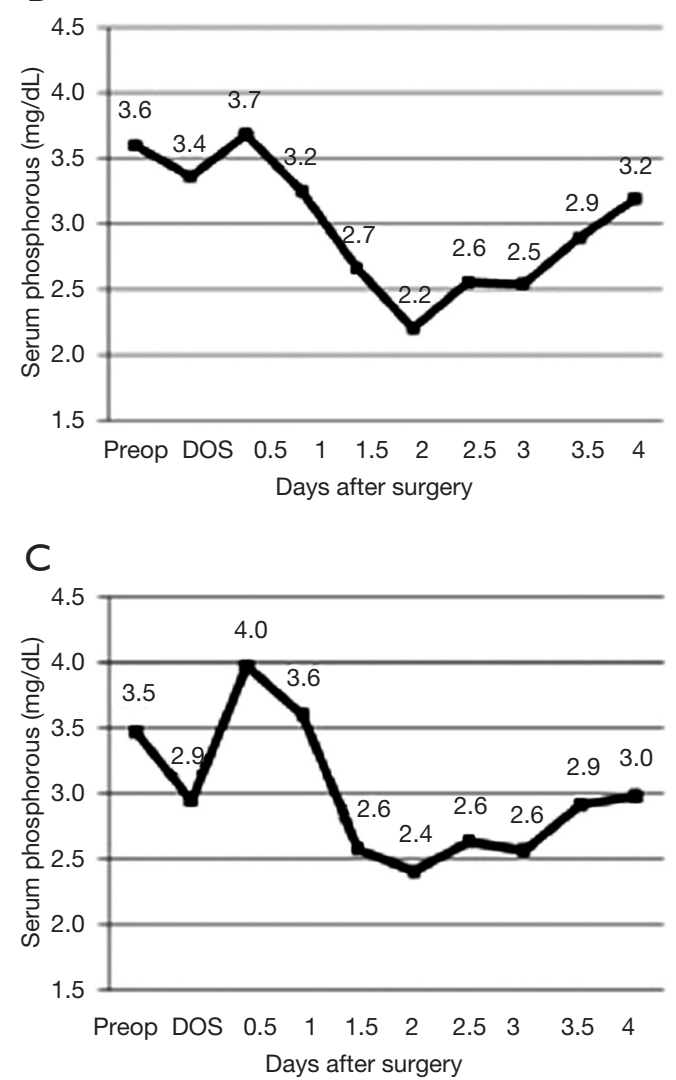

Figure 1 Serum phosphorus concentration after hepatectomy. Data is from 125 consecutive patients subjected to hepatectomy by one of the authors (Y Fong). Data is shown for all patients (A), major resections $(\mathrm{B})$, and minor resections $(\mathrm{C})$.

drains, post-operative fluid and electrolyte management, and contact with physician extenders following discharge. It should be noted that ERAS interventions are most effective as part of a multimodal ERP continuum that is designed to attenuate stress during a patient's perioperative journey and thus maintain preoperative physiologic and psychological baselines throughout the care continuum (5-7). Adequate ERPs begin with effective preoperative physician-patient communication, education, and "prehabilitation". ERPs are sustained by patient education in the perioperative hospital setting, and are completed by patient compliance both inhospital and at home which can be enriched by protocolized physician-extender patient contact in the post-operative setting. Figure 1 demonstrates the goals of an over-arching ERP for liver resection. The aim of this article is to review the current evidence for ERPs and peri-hepatectomy care, touch on minimally invasive interventions for hepatectomy, and explore future directions for meaningful research in this area.

\section{Evidence-based components of liver ERAS}

A review of evidence culminated from studies looking specifically at perioperative management of liver resection patients has yielded the formal recommendation of the factors listed in Table 1 as critical to effective liver ERAS programs by the ERAS Group (8-15). The following additional recommendations have been made by multiple ERAS investigators but with less robust evidentiary backing to date: Preoperative counseling, bowel stimulation with laxatives, early and scheduled mobilization, regular ERAS program audits, and use of a discharge coordinator or coach.

Post-operative ileus is of course a much greater focus in colorectal surgery, but also has a real role in perihepatectomy pathways. As one of the major causes of prolonged length of stay, it is also associated with increased all-cause morbidity regardless of procedure type (16). Efforts to decrease post-operative ileus include judicious use of opioids at all phases of perioperative care, in addition to adjunctive use of non-steroidal anti-inflammatories and epidural analgesia where clinically appropriate (17). Other anti-ileus strategies include encouraging early enteral nutrition as discussed in the Nutrition section. There is some evidence to advocate for use of clear carbohydrateladen drinks up to two hours before surgery to enhanced post-operative return of bowel function (18). Studies have also demonstrated improvement in post-operative insulin resistance and reductions of hunger and anxiety $(9,10,19)$. There is also weak evidence to promote the use of laxatives following liver resection (20). 
Table 1 Critical elements of liver ERP factors

Evidence-based recommendation (level 1 or 2 )
Pre-op Gl management
No bowel prep
Allow pre-op solids up to 6 hours
Allow pre-op liquid carbohydrate loading up to 2 hours
Anesthesia management
Minimize perioperative opioids
Consider epidural
Prevent post-op nausea/vomiting
Pre-op prophylaxis
Anti-thrombotic prophylaxis
Single-dose antibiotics
Avoid hypothermia
Maintain body temperature $>36{ }^{\circ} \mathrm{C}$ at all times
Normal food at will on POD\# 1
Drains
No post-op NGT
No routine drainage of peritoneal cavity

ERP, enhanced recovery pathway; GI, gastrointestinal; POD, post-operative day; Pre-op, preoperative; NGT, nasogastric tube; CVP, central venous pressure; NSAID, non-steroidal antiinflammatory; APAP, acetaminophen.

\section{Intraoperative management}

\section{Length of operation}

A short operation with rapid resuscitation of the patient likely plays as significant of a role in recovery as any other controllable factor. In the last three decades, it is well recognized that low CVP leads to less blood loss by controlling bleeding from the hepatic veins (21). Low CVP, however, may compromise cardiac output, splanchnic organ perfusion, and temperature control. Consequently, long periods of low CVP may lead to renal dysfunction, hypothermia, and bacterial translocation. As soon as the liver resection specimen is extracted, resuscitation using warm fluids should begin immediately. For those at particularly high risk for organ dysfunction, the hepatic veins draining the liver section to be resected may be clamped early in the procedure at their entry into the vena cava in order to allow even earlier resuscitation.

\section{NG tube}

Nasogastric tubes are not used post-operatively unless a simultaneous gastrointestinal operation requires decompression. An indwelling NG tube after surgery discourages early enteral intake and can be a source of fluid loss.

\section{Drains}

Abdominal drains are not used routinely given the conclusive results of three separate trials showing no benefit of routine drainage $(22,23)$. Prospective large series (24) have further confirmed that drains are not of benefit other than in specific circumstances. Furthermore, drains may complicate management post-operatively and can result in intra-abdominal infections and infected ascites. Our practice is abdominal drainage in the setting of (I) an infected field; (II) a persistent bile leak; (III) a diaphragm repair and presence of a thoracic drain; or (IV) a biliary anastomosis.

\section{Minimally invasive liver surgery}

Laparoscopic liver resection for peripheral lesions smaller than $5 \mathrm{~cm}$ in maximum dimension has long been accepted as the standard of care (25). The role of robotic liver surgery continues to evolve, but it is becoming an increasingly accepted modality and a valuable tool for many who wish to pursue major hepatic resections in a minimally invasive manner $(26,27)$. The available data suggests that when attempting major hepatectomy, robotic methods are more likely to result in completion of the operation in a minimally invasive manner (28). The advancement in robotic instrumentation has made increasingly complex resections feasible. Whether completed laparoscopically or robotically, minimally invasive liver surgery confers decreased length of stay, faster return to baseline function, and should thus be considered a critical element of perihepatectomy ERPs (29). 
Table 2 Comparison of hypophosphatemia-related complications after major liver resection

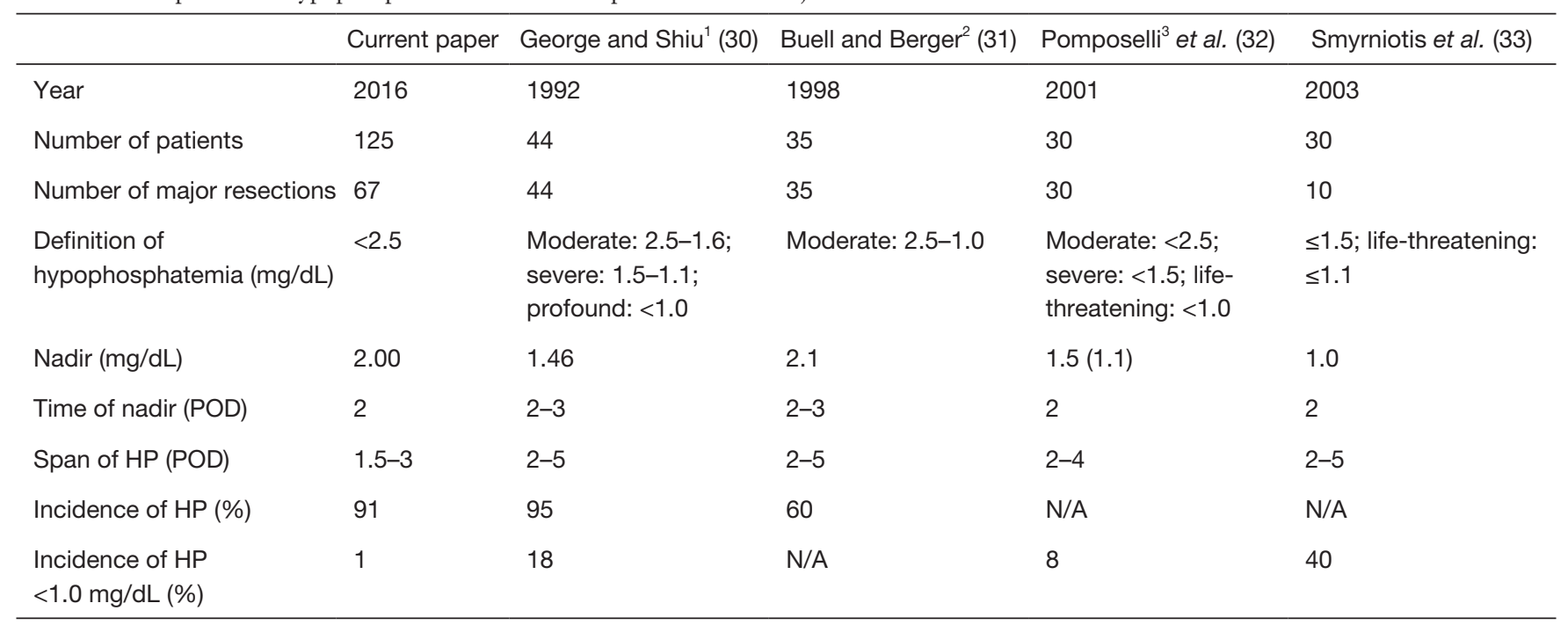

HP, cohort of patients who were hypophosphatemic in the post-operative period; nHP, cohort of patients who remained above the threshold for hypophosphatemia. ${ }^{1}$, limited their study to right and extended right lobectomies; ${ }^{2}$, included cryosurgery patients in their study; ${ }^{3}$, right hepatic lobectomy for live donor adult liver transplantation.

\section{Post-operative fluid, electrolyte, and transfusion management}

\section{Adequate resuscitation}

Fluid shifts occur with any major operation and are especially pronounced following liver resection given the necessity for low CVP. The additional inherent stress of hepatic dysfunction and regeneration can further potentiate the impact of fluid shifts. Surgeons promote varying approaches to post-hepatectomy fluid management, which commonly includes large volume fluid resuscitation in the initial 24 to 48 hours status post resection, followed by aggressive dieresis using a combination of loop and potassium sparing diuretics in an effort to minimize electrolyte shifts. Maintenance of euvolemia is critical to preserving renal function and preventing ascites. This is further evident in patients with cirrhosis who are more vulnerable to fluid shifts. Preoperative optimization and short anesthesia times can contribute to improved outcomes in these settings. The authors use blood urea nitrogen (BUN) as a measure of adequate fluid resuscitation, and try to ensure that patients gain no more than $5 \%$ of their preoperative body weight. Currently, there is limited data to support any one postoperative protocol, however, as enhanced recovery programs are propagated and more patients are approached in a protocolized manner, robust data will become available and lend itself to evidence-based guidelines.

\section{Phosphorous management}

Phosphorous is an important component of cell membranes and a significant intracellular ion. To our interest, phosphorous is necessary in the process of liver regeneration. Hypophosphatemia has long been noted during the clinical recovery from hepatectomy. Prior studies have demonstrated that hypophosphatemia is associated with post-operative complications (Table 2) (30-33). Specifically, hypophosphatemia below $1.0 \mathrm{mg} / \mathrm{dL}$ has been associated with major post-operative complications including cardiorespiratory complications, infections, hemorrhage, and liver failure (30). Supplementation up to $60 \mathrm{mEq}$ of phosphate a day has been shown to reduce complications (30).

Herein, the records of 125 patients treated by liver resection performed by one of the authors (Y Fong) were reviewed and reported. This cohort included 76 males, average age 57.4 years, and 63 major resections (removal of three segments or more of liver). Hypophosphatemia was defined as serum phosphorus level below $2.5 \mathrm{mg} / \mathrm{dL}$, while hyperphosphatemia was defined as serum phosphorus level above $4.2 \mathrm{mg} / \mathrm{dL}$. The nadir serum phosphorus level was also recorded. Phosphate supplementation was recorded 


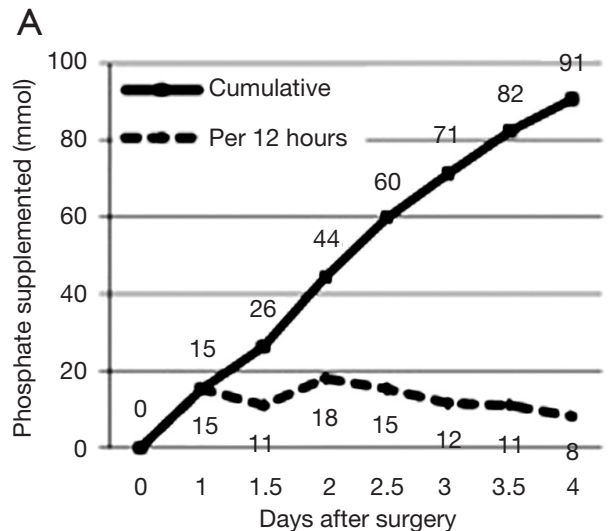

B

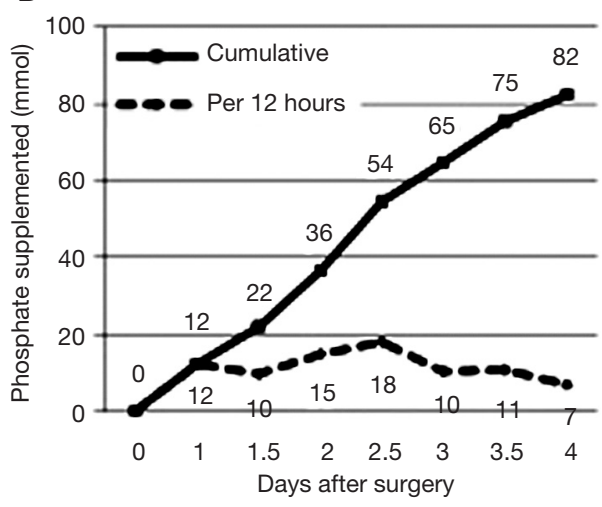

C

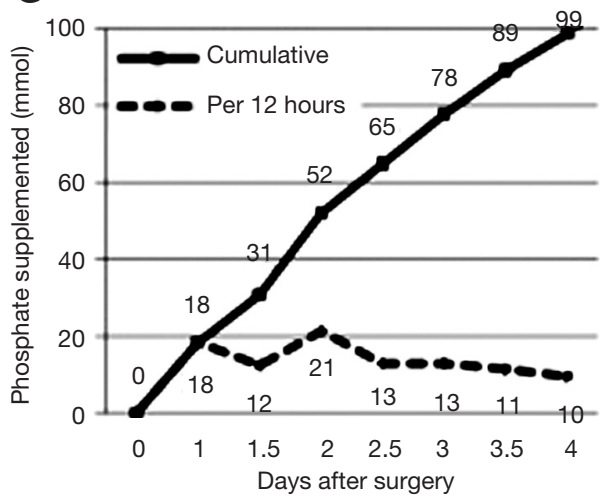

Figure 2 Phosphate supplementation after hepatectomy. Data is from 125 consecutive patients subjected to hepatectomy by one of the authors (Y Fong). Data is shown for all patients (A), major resections $(\mathrm{B})$, and minor resections $(\mathrm{C})$.

by total millimoles of sodium or potassium phosphate administered intravenously into twelve-hour time blocks. In cases when oral phosphate was given ("K-Phos" sodium/ potassium phosphate), one $250 \mathrm{mg}$ tablet was considered $8 \mathrm{mmol}$ in bioavailability.

\section{Course of hypophosphatemia}

Compared to the pre-operative level, there are two drops in serum phosphorus, observed within 2 and 48 hours of hepatic resection (Figure 1). Patients reached their nadir level on the second postoperative day (44 hours after surgery), which slowly rose to the normal phosphorus range over the third and fourth postoperative days. Hypophosphatemia spanned from POD 1.5 to 3, on average, for both major and minor resections (Figure 1). Despite phosphorous supplementation, the average drop in serum phosphorus was $41 \%$ compared to the pre-operative level. Major resections and minor resections showed a similar pattern of decline through the second post-operative day, however, the serum phosphorus level recovered more quickly among minor resections than among major resections (Figure 1). Early supplementation for minor resections is more likely to result in hyperphosphatemia (Figure 1C).

The distribution of nadir serum phosphorus levels was similar across all resections. Given the current practice of phosphorous supplementation, only $1 \%$ of patients reached phosphorus levels below $1.0 \mathrm{mg} / \mathrm{dL}$. This is a substantial improvement over past reported series (Table 2). In spite of supplementation, nearly $90 \%$ of patients were noted to have a phosphorous level less than $2.5 \mathrm{mg} / \mathrm{dL}$.

\section{Phosphate supplementation}

Most phosphate replacement was given within 12 and 48-60 hours of surgery (Figure 2), corresponding to times following the lowest serum concentrations, including the nadir on the second post-operative day. The cumulative amount of phosphate supplemented within the first four operative days was $91 \pm 9 \mathrm{mmol}$.

\section{Hypophosphatemia and complications}

Hypophosphatemic $(<2.5 \mathrm{mg} / \mathrm{dL})$ patients had a complication rate of $40 \%$, whereas patients whose phosphorus level remained in the normal range of $2.5-4.2 \mathrm{mg} / \mathrm{dL}$ had a lower complication rate of $27 \%$. Among patients undergoing minor resection, all major complications occurred in the hypophosphatemic group. Infection rate was higher in the cohort of patients whose nadir phosphorus fell below $1.5 \mathrm{mg} / \mathrm{dL}(14 \%$ vs. $6 \%, \mathrm{P}<0.05)$. Hypophosphatemia lasting more than two days showed a significant association with more complications among patients undergoing major resection $(43 \%$ vs. $12 \%$ complication rate, $\mathrm{P}<0.05)$. Interestingly, over-aggressive supplementation and hyperphosphatemia $(>4.2 \mathrm{mg} / \mathrm{dL})$ at any point in the first 
four post-op days was significantly related to complications across all magnitudes of resections.

Several published studies have noted the correlation between hypophosphatemia and post-operative complications following liver resection. George \& Shiu found higher complications in patients whose serum phosphorus level fell below $1.0 \mathrm{mg} / \mathrm{dL}$ (30). Buell \& Berger found a correlation for all levels of hypophosphatemia $(<2.5 \mathrm{mg} / \mathrm{dL})$ (31). In addition, Smyrniotis noted a significantly higher complication rate in patients whose levels fell to $\leq 1.5 \mathrm{mg} / \mathrm{dL}$ (33). Pomposelli showed that more aggressive post-operative TPN with twice the RDA of phosphorus (60 vs. $35 \mathrm{mmol} / \mathrm{d}$ ) resulted in half the incidence of complications in patients undergoing right hepatic lobectomy for live donor adult transplantation, although serum phosphorus levels were not reported in their study (32). George \& Shiu reported complications including cardiopulmonary depression, infection, hemorrhage, and liver failure $(30,31)$. Buell \& Berger identified complications such as pancreatitis, pulmonary infection, gastrointestinal hemorrhage, wound infection, and ileus in hypophosphatemic patients. Both George \& Shiu and Smyrniotis found that patients with hypophosphatemia had longer hospital stays.

Hypophosphatemia occurring post-hepatic resection has been well documented in previous studies (30-33). A number of physiologic changes contribute to the hypophosphatemia including the need for intracellular phosphorous in hepatocellular cell growth $(34,35)$ and post-operative disturbances in hepatorenal messaging, driving significant urinary losses of phosphate by a rise in a phosphatonin (36). Phosphate is an essential element for physiological homeostasis. The phosphate anion plays an important role in the formation of high-energy bonds essential for nucleotide synthesis, growth and repair of tissues, and the stability of the cell membrane (34). In addition, phosphate is essential for the proper function of red blood cells, platelets, and oxygen release from oxyhemoglobin (34). As such, post-operative hypophosphatemia has been linked to postoperative complications, including impaired diaphragmatic contractility, hemolytic anemia, myocardial depression, and glucose intolerance by insulin depression $(34,35)$.

With this knowledge, it has been standard to monitor serum phosphorus levels and employ phosphate replacement therapy after hepatic resection. The incidence of profound hypophosphatemia has decreased significantly since the George \& Shiu publication in 1992. Since that time, the rate of major complications among MSK patients undergoing major hepatic resection has decreased significantly from $32 \%$ to $21 \%$ ) (30). The rate of infection has also decreased from $18 \%$ to $9 \%$ (6). Only $1.7 \%$ of patients in our study reached phosphorus levels below $1.0 \mathrm{mg} / \mathrm{dL}$, which George \& Shiu defined as "profound hypophosphatemia" (30). Their study indicated that profound hypophosphatemia was significantly correlated with post-operative complications $(\mathrm{P}<0.001)(30)$. This indicates that we have been successful in close monitoring and early, aggressive phosphate replacement to keep this electrolyte in balance. Nevertheless, despite close monitoring and aggressive supplementation, $89 \%$ of patients undergoing hepatic resection fell into the hypophosphatemic range below $2.5 \mathrm{mg} / \mathrm{dL}$ in the postoperative period.

Previous studies have largely overlooked the incidence of hypophosphatemia in minor resections. Our study showed that phosphorus levels fluctuations follow a similar trend in patients undergoing either minor or major hepatic resections. Although slightly higher than the nadir of the major resection cohort, the nadir phosphorus level among minor resections also falls below $2.5 \mathrm{mg} / \mathrm{dL}$. Notably, all patients whose nadir fell below $2.5 \mathrm{mg} / \mathrm{dL}$ among minor resections experienced major complications. However, minor resections are supplemented less frequently on POD 1, likely due to the expectation that the patient's phosphorus level will not fall as dramatically after a minor resection.

We noted a trend toward more complications among both magnitudes of resections. In addition, we found a significant correlation between infections and nadir serum phosphorus below $1.5 \mathrm{mg} / \mathrm{dL}$ among major resections. This trend was not observed among minor resections, suggesting that the risk of infection may be associated with extent of resection.

These findings indicate that earlier, more aggressive phosphate replacement must be employed to prevent clinically significant hypophosphatemia. Safe supplementation has been suggested at $15 \mathrm{mmol}$ of IV sodium or potassium phosphate infused over 2-6 hours and repeated $2-3$ times in 24 hours $(30,34)$. However, overaggressive phosphate repletion has been linked to complications such as renal failure, hypocalcemic tetany, hypotension, and cardiac arrhythmias $(31,34,37)$. Since complication rates were observed in our study in cases where supplementation exceeded the recommended $45 \mathrm{mmol} / \mathrm{d}$ dose of supplementation, hyperphosphatemia may have been the cause of complications. We observed that there exists a threshold of phosphate supplementation above which the risks outweigh the benefits. This underscores the necessity to closely monitor and treat hypophosphatemia 
Table 3 Fluid and electrolyte resuscitation plan

\begin{tabular}{|c|c|c|c|c|}
\hline & Minor resection & Major resection & MIS resection & $\begin{array}{l}\text { Combined liver } \\
\text { intestinal surgery }\end{array}$ \\
\hline $\begin{array}{l}\text { Intra-operative } \\
\text { and day } 0\end{array}$ & $\begin{array}{l}\mathrm{NPO} \text {, isotonic balanced } \\
\text { solution (e.g., RL) until } \\
\text { resuscitated }\end{array}$ & $\begin{array}{l}\mathrm{NPO} \text {, isotonic balanced } \\
\text { solution (e.g., RL) until } \\
\text { resuscitated }\end{array}$ & $\begin{array}{l}\text { NPO, isotonic balanced } \\
\text { solution (e.g., RL) until } \\
\text { resuscitated }\end{array}$ & $\begin{array}{l}\mathrm{NPO} \text {, isotonic balanced } \\
\text { solution (e.g., RL) until } \\
\text { resuscitated }\end{array}$ \\
\hline POD 1 & $\begin{array}{l}\mathrm{D} 5 / 0.45 \mathrm{NS}+\mathrm{KCl} \\
20 \mathrm{meq} / \mathrm{L}^{*} ; \mathrm{PO} \text { as tolerated }\end{array}$ & $\begin{array}{l}\mathrm{D} 5 / 0.45 \mathrm{NS}+\mathrm{KPhos} \\
15 \mathrm{mmoles} / \mathrm{L}^{*} ; \mathrm{PO} \text { as } \\
\text { tolerated }\end{array}$ & $\begin{array}{l}\text { PO soft diet; IV directed by } \\
\text { size of resection }\end{array}$ & $\begin{array}{l}\text { PO directed by clinical } \\
\text { assessment of ileus; IV } \\
\text { directed by size of resection }\end{array}$ \\
\hline POD 2 & $\begin{array}{l}\text { D5/0.45 NS + KPhos } \\
30 \text { mmoles/L*; soft diet }\end{array}$ & $\begin{array}{l}\text { D5/0.45 NS + KPhos } \\
30 \text { mmoles/L*; soft diet }\end{array}$ & $\begin{array}{l}\mathrm{D} 5 / 0.45 \mathrm{NS}+\mathrm{KPhos} \\
30 \mathrm{mmoles} / \mathrm{L}^{*} \text {; soft diet; unless } \\
\text { discharged, then regular diet }\end{array}$ & $\begin{array}{l}\mathrm{D} 5 / 0.45 \mathrm{NS}+\mathrm{KPhos} \\
30 \mathrm{mmoles} / \mathrm{L}^{*} \text {; diet directed by } \\
\text { assessment of Gl function }\end{array}$ \\
\hline POD 3 & $\begin{array}{l}\text { D5/0.45 NS + KPhos } \\
15 \text { mmoles/L*; soft diet }\end{array}$ & $\begin{array}{l}\text { D5/0.45 NS + KPhos } \\
15 \text { mmoles/L*; soft diet }\end{array}$ & - & - \\
\hline
\end{tabular}

*, modify if diabetic or hyperkalemia/renal insufficiency. NPO, nil per os; RL, Ringer's lactate; POD, post-operative day; IV, intravenous; GI, gastrointestinal.

Table 4 Transfusion criteria for FFP

\begin{tabular}{lll}
\hline & Normal platelets, no aspirin or anti-platelet agents & Thrombocytopenic, on aspirin or other anti-platelets \\
\hline INR $<1$ & None & None \\
INR 1-1.5 & Vitamin K & Vitamin K \\
INR 1.5-2.0 & Vitamin K & Vitamin K and Transfuse FFP q 12 hours \\
INR $>2$ & Vitamin K and Transfuse FFP q 12 hours & Vitamin K and Transfuse FFP q 12 hours \\
\hline
\end{tabular}

FFP, fresh frozen plasma.

among all patients post hepatic resection. A recommended plan for fluid and phosphorous administration is shown in Table 3.

\section{Transfusion}

Two decades ago, the practice of fresh frozen plasma (FFP) transfusion after major liver resection was routine. As energy sealers, staplers, and sutures have become more secure for ligation of major vessel and parenchymal transection, routine transfusion of clotting factors via FFP is less often necessary (38). A recommended practice is shown in Table 4, taking into account the patient's risk of bleeding, platelet functional status, and liver function.

\section{Nutrition}

Most ERPs incorporate preoperative carbohydrate loading two hours prior to the operation with products such as clear fast and advocate for oral intake (of liquids) within 4-6 hours postoperatively. In fact, there is relatively weak evidence to support the practice of carbohydrate loading in advance of surgery, but afterward it is clear that early introduction of enteral nutrition can reduce overall morbidity and specifically septic complications (39-42). Following hepatic resections, patients are in a catabolic state characterized by glucose and electrolyte imbalances mitigated by increased metabolic demand (43). Some surgeons advocate the use of glucose containing fluids in the post-resection resuscitation algorithms in order to abrogate the catabolism. There is also a growing body of evidence supporting use of branched chain amino acid supplementation in the perioperative setting $(44,45)$. This also has yet to become part of any sort of widespread recommendations but is something to be considered in future investigations. 


\begin{tabular}{|c|c|}
\hline PREOP & $\begin{array}{l}\text { Assessments } \\
* \text { Social support } \\
* \text { Nutrition } \\
* \text { Fitness \& sleep } \\
* \text { Mental health } \\
\text { * Liver function }\end{array}$ \\
\hline HOSPITAL & $\begin{array}{l}\text { Interventions } \\
* \text { Post-operative care protocols } \\
\text { * Individualized activity goals } \\
\text { * Standardized diet \& bowel care } \\
\text { * Minimize narcotics } \\
\text { Assessments } \\
* \text { Social support } \\
\text { * Nutrition } \\
\text { * Sleep \& activity } \\
\text { * Mental health } \\
\text { * Liver function }\end{array}$ \\
\hline $\begin{array}{l}\text { POST- } \\
\text { DISCHARGE }\end{array}$ & $\begin{array}{l}\text { * Regular assessments by social work and } \\
\text { physician extender } \\
\text { - More frequent with high-risk patients } \\
\text { Interventions as indicated based on assessment } \\
\text { needs } \\
\text { - Examples: encourage increased activity } \\
\text { - Involve mental health professionals early } \\
\text { - Monitor and manage pain } \\
\text { - Continued nutritional counseling } \\
\text { - Social support tools as needed }\end{array}$ \\
\hline
\end{tabular}

Figure 3 Components of liver ERP. ERP, enhanced recovery pathway.

\section{Stratifying risk}

As Western centers move toward ERPs and have reimbursements linked to outcomes and length of stay, clinicians must be conscious of patients at higher risk for readmission. Readmission rates can be particularly high after major hepatectomy, with modern series reporting up to $19 \%$ of patients returning within 90 days of surgery $(46,47)$. It is important to consider risk factors and implement safeguards for patients that are more likely to require support in the post-hospital, post-operative setting. For instance, patients who have low baseline albumin, history of vascular disease, receive transfusion within 72 hours of surgery, have excessive intraoperative blood loss, experience any post-operative complications, develop intraabdominal infection, or have longer operative times, are more likely to experience unplanned readmissions (46-48). Future coordinated efforts are needed to develop a more protocolized approach to score and identify and treat at-risk post-operative patients. Many health systems are employing patient navigators or other at-home patient contact at regular intervals outside of the one anticipated postoperative visit. This should be more closely examined in the peri-hepatectomy population.

\section{Outcome measures}

Length of stay (LOS) and time to functional recovery are two of the more commonly employed outcome measures. Several well performed studies have indicated substantial decreases in LOS following ERP implementation $(20,49)$. That being said, LOS is not always the best measure of successful ERP because increased LOS can be mediated by a number of factors not related to the ERP. Studies looking at patients who failed to leave despite ERP have shown that common reasons for staying later include concern for complications, extensive surgery, low patient confidence, and transport-related or other social problems $(20,49)$. Studies emphasizing mobility show that full mobilization can be achieved by up to $85 \%$ of patients by post-operative day 3 (4). Studies have also examined readmission rates to ensure that the accelerated care does not compromise a patient's self-care at home (50). As of yet, peri-hepatectomy ERPs are not consistently associated with improved morbidity or survival, but there is no evidence that these numbers are increased in ERP patients. Analyzing these outcomes will be important for future studies.

\section{Future directions \& discussion}

ERPs in the peri-hepatectomy setting are gaining acceptance as a useful adjunct to current post-operative care. A recent meta-analysis of nine articles including two randomized controlled trials demonstrated that length of stay and complications rates were significantly reduced by ERPs (51). The studies reviewed showed that advanced age and American Society of Anesthesiologists (ASA) class are independent predictors of morbidity following abdominal surgery (52). They also showed that even more complex protocols with up to 19 components could be adhered to (53). One criticism of the currently available ERP research is the lack of evaluation of patient functional recovery. Any measure of the efficacy of ERPs should evaluate patient perceptions and quality of life (QOL) (54). However, a minority of studies looking at post-operative progress following employment of ERPs after abdominal surgery include QOL measures. Further studies are needed to ensure that ERPs are appropriately patient-centered and that validated QOL tools contribute to measurements of protocol success. Figure 3 demonstrates a schema for 
a comprehensive set of perioperative assessments and interventions that could ultimately be incorporated into a successful ERP. Other endpoints include return to function-though what this means also must be defined. A generally accepted combination of components in the literature include: pain controlled with oral medications, tolerating oral intake and adequately hydrated without intravenous fluids, passing flatus and/or stool, mobility at or near preoperative level. These are different than the criteria for discharge which are noted in Table 5 .

In addition to QOL-based studies, it will be critical in the future to establish protocolized fluid and electrolyte management with some semblance of uniformity across institutions so that we as a profession can standardize and

Table 5 Discharge criteria

\section{Criterion}

Normal or down-trending transaminases \& bilirubin

Adequate PO nutrition \& hydration

Off IV fluids

Independently mobile

Urinating independently or educated re: straight catheter

No evidence of bowel dysfunction (for MIS cases, flatus not required)

Post-operative appointments made

Discharge documents/instructions faxed to PCP

Demonstrates understanding of self-care and home support

PO, per os; IV, intravenous; MIS, minimally invasive surgery; $\mathrm{PCP}$, primary care physician. ultimately optimize peri-hepatectomy care. Finally, more research into the identification of high-risk individuals, and standardized interventions to mitigate readmission risks. Ideal standardized endpoints for future peri-hepatectomy ERP trials are listed in Table 6.

\section{Conclusions}

Research regarding best practice standards for ERPs in the peri-hepatectomy setting continues to build and expert recommendations continue to evolve. What is clear is that careful, coordinated, interdisciplinary, data-driven protocolized management of patients before, during, and after hepatectomy results in decreased stress on the patient physiologically and psychosocially. We should aim toward protocolizing this experience across all centers. A recommended set of ERAS pathways is provided in Table 7 .

Table 6 Study endpoints for future enhanced recovery protocol studies

Outcome endpoints
Length of stay
Return to baseline function
Time from surgery to chemotherapy (when resection for
malignancy)
Post-operative complications
Disease-free \& overall survival
Readmission
Quality of life

Table 7 COH liver resection ERAS protocol

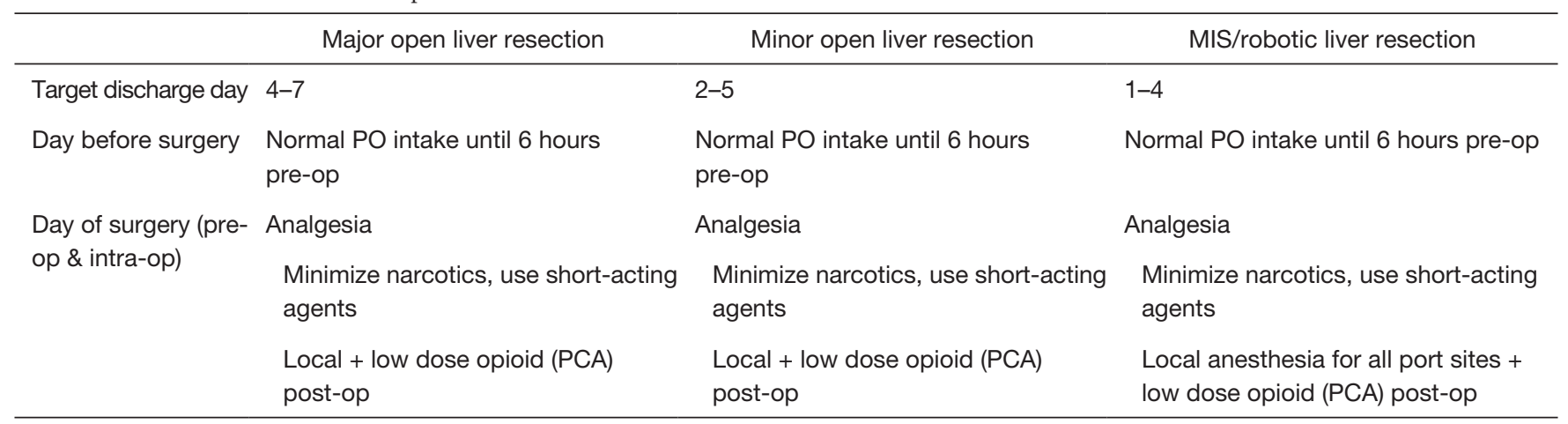

Table 7 (continued) 
Table 7 (continued)

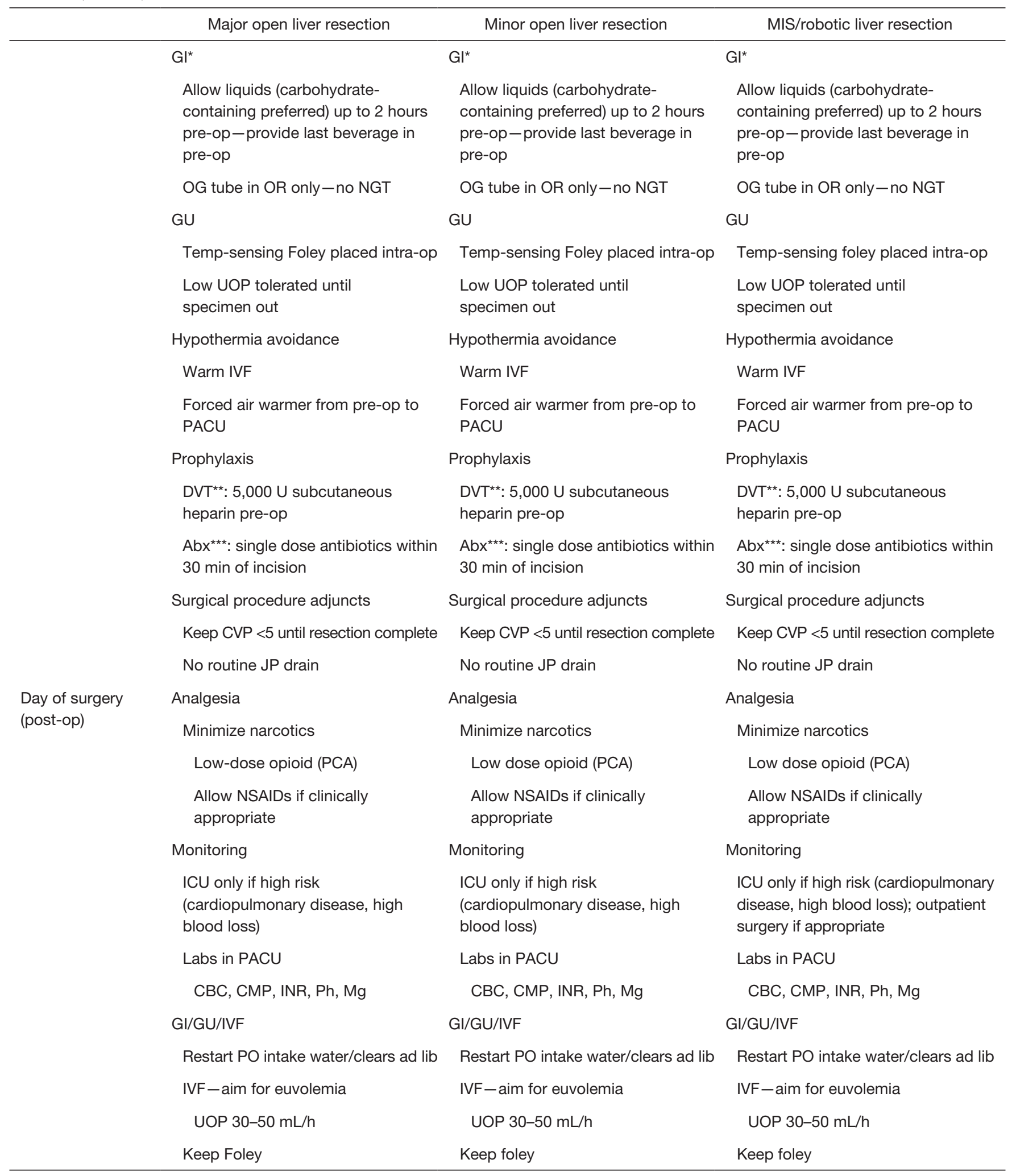

Table 7 (continued) 
Table 7 (continued)

\begin{tabular}{|c|c|c|c|}
\hline & Major open liver resection & Minor open liver resection & MIS/robotic liver resection \\
\hline \multirow{12}{*}{ Post-op day \#1 } & Minimize narcotics & Minimize narcotics & Minimize narcotics \\
\hline & Low dose opioid (PCA) & $\begin{array}{l}\text { Low dose opioid }(\mathrm{PCA})- \\
\text { transition to PO pain meds in PM } \\
\text { if tolerating diet }\end{array}$ & $\begin{array}{l}\text { Low dose opioid (PCA) - transition } \\
\text { to PO pain meds in AM if } \\
\text { tolerating diet }\end{array}$ \\
\hline & $\begin{array}{l}\text { Hold NSAIDs for platelets }<100 \\
\text { or Creatinine }>1.5\end{array}$ & $\begin{array}{l}\text { Hold NSAIDs for platelets }<100 \\
\text { or Creatinine }>1.5\end{array}$ & $\begin{array}{l}\text { Hold NSAIDs for platelets }<100 \\
\text { or Creatinine }>1.5\end{array}$ \\
\hline & Hold APAP for LFTs $>500$ & Hold APAP for LFTs $>500$ & Hold APAP for LFTs $>500$ \\
\hline & Labs & Labs & Labs \\
\hline & CBC, CMP, INR, Ph\#, Mg & $\mathrm{CBC}, \mathrm{CMP}, \mathrm{INR}, \mathrm{Ph}, \mathrm{Mg}$ & CBC, CMP, INR, Ph\#, Mg \\
\hline & $\mathrm{Gl} / \mathrm{GU} / \mathrm{IVF} / \mathrm{Ppx}$ & $\mathrm{Gl} / \mathrm{GU} / \mathrm{IVF} / \mathrm{Ppx}$ & $\mathrm{Gl} / \mathrm{GU} / \mathrm{IVF} / \mathrm{Ppx}$ \\
\hline & Resume regular soft diet & Resume regular soft diet & Resume regular soft diet \\
\hline & $\begin{array}{l}\text { IVF-switch to fluids in Table } 3 \\
\text { when euvolemia }\end{array}$ & $\begin{array}{l}\text { IVF-switch to fluids in Table } 3 \\
\text { when euvolemia }\end{array}$ & $\begin{array}{l}\text { IVF-switch to fluids in Table } 3 \text { when } \\
\text { euvolemia }\end{array}$ \\
\hline & $\begin{array}{l}\text { D/c foley unless BPH symptoms at } \\
\text { baseline }\end{array}$ & D/c foley & D/c foley \\
\hline & $\begin{array}{l}\text { Out of bed } \times 4-\text { with PT if pre-op } \\
\text { debilitation }\end{array}$ & $\begin{array}{l}\text { Out of bed } \times 4-\text { with PT if pre-op } \\
\text { debilitation }\end{array}$ & Out of bed $\times 4$ \\
\hline & $\begin{array}{l}\text { Can base debilitation on certain } \\
\text { Karnofsky or ECOG score }\end{array}$ & $\begin{array}{l}\text { Can base debilitation on certain } \\
\text { Karnofsky or ECOG score }\end{array}$ & Discharge if criteria met \\
\hline \multirow[t]{7}{*}{ Post-op day \#2 } & Analgesia & Analgesia & Analgesia \\
\hline & Minimize narcotics & Minimize narcotics & Minimize narcotics \\
\hline & Oral pain meds if tolerating diet & Oral pain meds if tolerating diet & Oral pain meds if tolerating diet \\
\hline & $\begin{array}{l}\text { Continue scheduled NSAIDs \& APAP } \\
\text { unless medically contraindicated }\end{array}$ & $\begin{array}{l}\text { Continue scheduled NSAIDs \& APAP } \\
\text { unless medically contraindicated }\end{array}$ & $\begin{array}{l}\text { Continue scheduled NSAIDs \& APAP } \\
\text { unless medically contraindicated }\end{array}$ \\
\hline & Monitoring & Monitoring & Monitoring \\
\hline & Labs q12h & Labs q12h & Labs q12h \\
\hline & CBC, CMP, INR, Ph\#, Mg & CBC, CMP, INR, Ph\#, Mg & $\mathrm{CBC}, \mathrm{CMP}, \mathrm{INR}, \mathrm{Ph} \#, \mathrm{Mg}$ \\
\hline
\end{tabular}

Table 7 (continued) 
Table 7 (continued)

\begin{tabular}{|c|c|c|c|}
\hline & Major open liver resection & Minor open liver resection & MIS/robotic liver resection \\
\hline & Continue regular diet & Continue regular diet & Continue regular diet \\
\hline & IV fluids as per Table 3 & IV fluids as per Table 3 & IV fluids as per Table 3 \\
\hline & $\mathrm{D} / \mathrm{c}$ foley if not already done & $\mathrm{D} / \mathrm{c}$ foley if not already done & D/c foley if not already done \\
\hline & Colace \pm laxative & Colace \pm laxative & Colace \pm laxative \\
\hline & BID subcutaneous heparin $5,000 \mathrm{U}$ & BID subcutaneous heparin $5,000 \mathrm{U}$ & BID subcutaneous heparin $5,000 \mathrm{U}$ \\
\hline & Activity & Activity & Activity \\
\hline & $\begin{array}{l}\text { Out of bed } \times 4-\text { with PT if pre-op } \\
\text { debilitation }\end{array}$ & $\begin{array}{l}\text { Out of bed } \times 4 \text {-with PT if pre-op } \\
\text { debilitation }\end{array}$ & $\begin{array}{l}\text { Out of bed } \times 4 \text {-with PT if pre-op } \\
\text { debilitation }\end{array}$ \\
\hline \multirow{10}{*}{ Post-op day \#3 } & Minimize narcotics & & \\
\hline & Oral pain meds & & \\
\hline & $\begin{array}{l}\text { Continue scheduled NSAIDs } \\
\text { \& APAP unless medically } \\
\text { contraindicated }\end{array}$ & & \\
\hline & Monitoring & & \\
\hline & Labs & & \\
\hline & CBC, CMP, INR, Ph\#, Mg & & \\
\hline & BID subcutaneous heparin $5,000 \mathrm{U}$ & & \\
\hline & Activity & & \\
\hline & $\begin{array}{l}\text { Out of bed } \times 4-\text { with PT if pre-op } \\
\text { debilitation }\end{array}$ & & \\
\hline & May discharge if criteria met & & \\
\hline \multirow[t]{2}{*}{ Post-op day \#4-7 } & $\begin{array}{l}\text { Complete any of requisite discharge } \\
\text { criteria holding patient back }\end{array}$ & - & - \\
\hline & Discharge home & & \\
\hline
\end{tabular}

*, GI prophylaxis if major EBL, aspiration, or on antacids pre-operatively; ${ }^{*}$, DVT prophylaxis may not be used if patient is on antiplatelet agent, if there is concern for high risk of surgical bleeding; ${ }^{* \star}$, more than 1 dose of antibiotics if presence of biliary stents or history of infection. In those cases of infection, particularly if post-operative ascites is anticipated, antibiotics for 72 hours until intraoperative cultures can be used to direct treatment or discontinuation of antibiotics. \#, additional KPhos supplement informed by serum levels: 15 mmol over 2-4 hours if Phos level $<2.5 \mathrm{mg} / \mathrm{dL}$; $30 \mathrm{mmol}$ over $2-4$ hours for Phos level $<2.0 \mathrm{mg} / \mathrm{d}$. COH, City of Hope; ERAS, Enhanced Recovery After Surgery. 


\section{Acknowledgements}

None.

\section{Footnote}

Conflicts of Interest: The authors have no conflicts of interest to declare.

\section{References}

1. Greco M, Capretti G, Braga M. Enhanced Recovery Program in Colorectal Surgery: A Meta-analysis of Randomized Controlled Trials. World J Surg 2014;38:1531-41.

2. Gatt M, Khan S, MacFie J. In response to: Varadhan KK, Neal KR, Dejong CH, Fearon KC, Ljungqvist O, Lobo DN. The enhanced recovery after surgery (ERAS) pathway for patients undergoing major elective open colorectal surgery: a meta-analysis of randomized controlled trials. Clin Nutr 29 (2010) 434-440. Clin Nutr 2010;29:689-90; author reply 691-2.

3. Grocott MP, Martin DS, Mythen MG. Enhanced recovery pathways as a way to reduce surgical morbidity. Curr Opin Crit Care 2012;18:385-92.

4. van Dam RM, Hendry PO, Coolsen MM, et al. Initial experience with a multimodal enhanced recovery programme in patients undergoing liver resection. $\mathrm{Br} \mathrm{J}$ Surg 2008;95:969-75.

5. Gouin JP, Kiecolt-Glaser JK. The impact of psychological stress on wound healing: methods and mechanisms. Immunol Allergy Clin North Am 2011;31:81-93.

6. Melnyk M, Casey RG, Black P, et al. Enhanced recovery after surgery (ERAS) protocols: Time to change practice? Can Urol Assoc J 2011;5:342-8.

7. Walburn J, Vedhara K, Hankins M, et al. Psychological stress and wound healing in humans: a systematic review and meta-analysis. J Psychosom Res 2009;67:253-71.

8. Coolsen MM, Wong-Lun-Hing EM, van Dam RM, et al. A systematic review of outcomes in patients undergoing liver surgery in an enhanced recovery after surgery pathways. HPB (Oxford) 2013;15:245-51.

9. Ljungqvist $\mathrm{O}$, Nygren J, Thorell A. Modulation of postoperative insulin resistance by pre-operative carbohydrate loading. Proc Nutr Soc 2002;61:329-36.

10. Hausel J, Nygren J, Lagerkranser M, et al. A carbohydraterich drink reduces preoperative discomfort in elective surgery patients. Anesth Analg 2001;93:1344-50.
11. Helminen H, Viitanen H, Sajanti J. Effect of preoperative intravenous carbohydrate loading on preoperative discomfort in elective surgery patients. Eur J Anaesthesiol 2009;26:123-7.

12. American Society of Anesthesiologists Committee. Practice guidelines for preoperative fasting and the use of pharmacologic agents to reduce the risk of pulmonary aspiration: application to healthy patients undergoing elective procedures: an updated report by the American Society of Anesthesiologists Committee on Standards and Practice Parameters. Anesthesiology 2011;114:495-511.

13. Gurusamy KS, Samraj K, Davidson BR. Routine abdominal drainage for uncomplicated liver resection. Cochrane Database Syst Rev 2007;(3):CD006232.

14. Petrowsky H, Demartines N, Rousson V, et al. Evidencebased value of prophylactic drainage in gastrointestinal surgery: a systematic review and meta-analyses. Ann Surg 2004;240:1074-84; discussion 1084-5.

15. Pessaux P, Regimbeau JM, Dondero F, et al. Randomized clinical trial evaluating the need for routine nasogastric decompression after elective hepatic resection. Br J Surg 2007;94:297-303

16. Luckey A, Livingston E, Tache Y. Mechanisms and treatment of postoperative ileus. Arch Surg 2003;138:206-14.

17. Kehlet H, Rung GW, Callesen T. Postoperative opioid analgesia: time for a reconsideration? J Clin Anesth 1996;8:441-5

18. Noblett SE, Watson DS, Huong H, et al. Pre-operative oral carbohydrate loading in colorectal surgery: a randomized controlled trial. Colorectal Dis 2006;8:563-9.

19. Helminen H, Viitanen H, Sajanti J. Effect of preoperative intravenous carbohydrate loading on preoperative discomfort in elective surgery patients. Eur J Anaesthesiol 2009;26:123-7.

20. Hendry PO, van Dam RM, Bukkems SF, et al. Randomized clinical trial of laxatives and oral nutritional supplements within an enhanced recovery after surgery protocol following liver resection. Br J Surg 2010;97:1198-206.

21. Melendez J, Ferri E, Zwillman M, et al. Extended hepatic resection: a 6-year retrospective study of risk factors for perioperative mortality. J Am Coll Surg 2001;192:47-53.

22. Fong $\mathrm{Y}$, Brennan MF, Brown $\mathrm{K}$, et al. Drainage is unnecessary after elective liver resection. Am J Surg 1996;171:158-62.

23. Burt BM, Brown K, Jarnagin W, et al. An audit of results of a no-drainage practice policy after hepatectomy. Am J 
Surg 2002;184:441-5.

24. Squires MH 3rd, Lad NL, Fisher SB, et al. Value of primary operative drain placement after major hepatectomy: a multi-institutional analysis of 1,041 patients. J Am Coll Surg 2015;220:396-402.

25. Buell JF, Cherqui D, Geller DA, et al. The international position on laparoscopic liver surgery: The Louisville Statement, 2008. Ann Surg 2009;250:825-30.

26. Leung U, Fong Y. Robotic liver surgery. Hepatobiliary Surg Nutr 2014;3:288.

27. Kingham TP, Leung U, Kuk D, et al. Robotic Liver Resection: A Case-Matched Comparison. World J Surg. 2016;40:1422-8.

28. Tsung A, Geller DA, Sukato DC, et al. Robotic versus laparoscopic hepatectomy: a matched comparison. Ann Surg 2014;259:549-55.

29. Alkhalili E, Berber E. Laparoscopic liver resection for malignancy: a review of the literature. World J Gastroenterol 2014;20:13599-606.

30. George R, Shiu MH. Hypophosphatemia after major hepatic resection. Surgery 1992;111:281-6.

31. Buell JF, Berger AC, Plotkin JS, et al. The clinical implications of hypophosphatemia following major hepatic resection or cryosurgery. Arch Surg 1998;133:757-61.

32. Pomposelli JJ, Pomfret EA, Burns DL, et al. Lifethreatening hypophosphatemia after right hepatic lobectomy for live donor adult liver transplantation. Liver Transpl 2001;7:637-42.

33. Smyrniotis V, Kostopanagiotou G, Katsarelias D, et al. Changes of serum phosphorus levels in hepatic resections and implications on patients' outcomes. Int Surg 2003;88:100-4.

34. Brunelli SM, Goldfarb S. Hypophosphatemia: clinical consequences and management. J Am Soc Nephrol 2007;18:1999-2003.

35. Wrighton LJ, O'Bosky KR, Namm JP, et al. Postoperative management after hepatic resection. J Gastrointest Oncol 2012;3:41-7.

36. Salem RR, Tray K. Hepatic resection-related hypophosphatemia is of renal origin as manifested by isolated hyperphosphaturia. Ann Surg 2005;241:343-8.

37. Shroff R. Phosphate is a vascular toxin. Pediatr Nephrol 2013;28:583-93.

38. Martin RC, Jarnagin WR, Fong Y, et al. The use of fresh frozen plasma after major hepatic resection for colorectal metastasis: is there a standard for transfusion? J Am Coll Surg 2003;196:402-9.
39. Fan ST, Lo CM, Lai EC, et al. Perioperative nutritional support in patients undergoing hepatectomy for hepatocellular carcinoma. N Engl J Med 1994;331:1547-52.

40. Shirabe K, Matsumata T, Shimada M, et al. A comparison of parenteral hyperalimentation and early enteral feeding regarding systemic immunity after major hepatic resection--the results of a randomized prospective study. Hepatogastroenterology 1997;44:205-9.

41. Mochizuki H, Togo S, Tanaka K, et al. Early enteral nutrition after hepatectomy to prevent postoperative infection. Hepatogastroenterology 2000;47:1407-10.

42. Okabayashi T, Nishimori I, Sugimoto T, et al. Effects of branched-chain amino acids-enriched nutrient support for patients undergoing liver resection for hepatocellular carcinoma. J Gastroenterol Hepatol 2008;23:1869-73.

43. Ciuni R, Biondi A, Grosso G, et al. Nutritional aspects in patient undergoing liver resection. Updates Surg 2011;63:249-52.

44. Kim SJ, Kim DG, Lee MD. Effects of branched-chain amino acid infusions on liver regeneration and plasma amino acid patterns in partially hepatectomized rats. Hepatogastroenterology 2011;58:1280-5.

45. Ishikawa Y, Yoshida H, Mamada Y, et al. Prospective randomized controlled study of short-term perioperative oral nutrition with branched chain amino acids in patients undergoing liver surgery. Hepatogastroenterology 2010;57:583-90.

46. Egger ME, Squires MH 3rd, Kooby DA, et al. Risk stratification for readmission after major hepatectomy: development of a readmission risk score. J Am Coll Surg 2015;220:640-8.

47. Kimbrough CW, Agle SC, Scoggins CR, et al. Factors predictive of readmission after hepatic resection for hepatocellular carcinoma. Surgery 2014;156:1039-46.

48. Kim S, Maynard EC, Shah MB, et al. Risk factors for 30-day readmissions after hepatectomy: analysis of 2444 patients from the ACS-NSQIP database. J Gastrointest Surg 2015;19:266-71.

49. Slim K, Nini E, Forestier D, et al. Methodological index for non-randomized studies (minors): development and validation of a new instrument. ANZ J Surg 2003;73:712-6.

50. Hall TC, Dennison AR, Bilku DK, et al. Enhanced recovery programmes in hepatobiliary and pancreatic surgery: a systematic review. Ann R Coll Surg Engl 2012;94:318-26.

51. Hughes MJ, McNally S, Wigmore SJ. Enhanced recovery 
following liver surgery: a systematic review and metaanalysis. HPB (Oxford) 2014;16:699-706.

52. Feroci F, Lenzi E, Baraghini M, et al. Fast-track surgery in real life: how patient factors influence outcomes and compliance with an enhanced recovery clinical pathway after colorectal surgery. Surg Laparosc Endosc Percutan Tech 2013;23:259-65.

Cite this article as: Warner SG, Jutric Z, Nisimova L, Fong Y. Early recovery pathway for hepatectomy: data-driven liver resection care and recovery. HepatoBiliary Surg Nutr 2017;6(5):297-311. doi: 10.21037/hbsn.2017.01.18
53. Ahmed J, Khan S, Lim M, et al. Enhanced recovery after surgery protocols - compliance and variations in practice during routine colorectal surgery. Colorectal Dis 2012;14:1045-51.

54. Neville A, Lee L, Antonescu I, et al. Systematic review of outcomes used to evaluate enhanced recovery after surgery. Br J Surg 2014;101:159-70. 